\title{
Nitrate Supply-Dependent Shifts in Communities of Root-Associated Bacteria in Arabidopsis
}

\author{
NORIYUKI KONISHI ${ }^{1,2 *}$, TAKASHI OKUBO ${ }^{3}$, TOMOYUKI YAMAYA ${ }^{2}$, TOSHIHIKO HAYAKAWA ${ }^{1}$, and KIWAMU MinAMISAWA ${ }^{4}$ \\ ${ }^{1}$ Graduate School of Agricultural Science, Tohoku University, 468-1 Aramaki Aza Aoba, Sendai, Miyagi 980-0845, Japan; \\ ${ }^{2}$ Division for Interdisciplinary Advanced Research and Education, Tohoku University, 6-3 Aramaki Aza Aoba, Aoba-ku, Sendai, \\ Miyagi 980-8578, Japan; ${ }^{3}$ Institute for Agro-Environmental Sciences, National Agriculture and Food Research Organization, 3-1-3 \\ Kannondai, Tsukuba, Ibaraki 305-8604, Japan; and ${ }^{4}$ Graduate School of Life Sciences, Tohoku University, Katahira, 2-1-1 Aoba-ku, \\ Sendai, Miyagi 980-8577, Japan
}

(Received February 22, 2017-Accepted August 13, 2017_Published online November 30, 2017)

Root-associated bacterial communities are necessary for healthy plant growth. Nitrate is a signal molecule as well as a major nitrogen source for plant growth. In this study, nitrate-dependent alterations in root-associated bacterial communities and the relationship between nitrate signaling and root-associated bacteria in Arabidopsis were examined. The bacterial community was analyzed by a ribosomal RNA intergenic spacer analysis (RISA) and 16S rRNA amplicon sequencing. The Arabidopsis root-associated bacterial community shifted depending on the nitrate amount and timing of nitrate application. The relative abundance of operational taxonomic units of $25.8 \%$ was significantly changed by the amount of nitrate supplied. Moreover, at the family level, the relative abundance of several major root-associated bacteria including Burkholderiaceae, Paenibacillaceae, Bradyrhizobiaceae, and Rhizobiaceae markedly fluctuated with the application of nitrate. These results suggest that the application of nitrate strongly affects root-associated bacterial ecosystems in Arabidopsis. Bulk soil bacterial communities were also affected by the application of nitrate; however, these changes were markedly different from those in root-associated bacteria. These results also suggest that nitrate-dependent alterations in root-associated bacterial communities are mainly affected by plant-derived factors in Arabidopsis. T-DNA insertion plant lines of the genes for two transcription factors involved in nitrate signaling in Arabidopsis roots, NLP7 and TCP20, showed similar nitrate-dependent shifts in root-associated bacterial communities from the wild-type, whereas minor differences were observed in root-associated bacteria. Thus, these results indicate that NLP7 and TCP20 are not major regulators of nitrate-dependent bacterial communities in Arabidopsis roots.

Key words: root-associated bacterial communities, Arabidopsis, nitrate, NIN-like protein, TCP20

Root-associated microbes, including endophytes and epiphytes, are crucial for healthy plant growth because they promote nutrient acquisition and stress tolerance $(5,8,50$, 58). Thus, plant-associated microbes contribute to sustainable agriculture (57). In modern agriculture, nitrogen fertilizers are generally needed in order to attain high crop yields; however, previous studies demonstrated that this form of fertilization often changes microbial communities associated with plants, including soybean $(23,24)$, rice $(14,51,56)$, maize (18, 43), wheat (42), and sugarcane (60). Nitrate, which is the dominant nitrogen form in aerobic soil, is a major nitrogen source for plant growth, but also functions as a signal molecule in plants $(2,45)$. Thus, nitrate is regarded as a key compound that affects plant-microbe relationships (23).

Nitrate-dependent symbiotic relationships between legumes and rhizobia are regulated by the nodule inception (NIN) transcription factor $(54,55)$, several glycopeptides $(37,39)$, and certain phytohormones $(9,16)$. However, limited information is currently available on the factors regulating nitrate-dependent relationships among root-associated bacteria and non-legume plants.

The molecular mechanisms underlying plant nitrate signaling have been intensively examined over the last decade using Arabidopsis thaliana as a model. Nitrate signaling is mediated by the transcription factors ANR1 $(17,41,61)$, LBD37/38/39

\footnotetext{
* Corresponding author. E-mail: sakasen89@gmail.com; Tel: +81-(0)22-757-4278; Fax: +81-(0)22-757-4277.
}

(44), NLP6/7 (28, 34), SPL9 (30), TGA1/4 (1), and TCP20 (19), by the nitrate transporter NRT1.1 (59), by the kinases CIPK8 and CIPK23 $(21,22)$, by cytokinins $(27,49)$, and by glycopeptides (3). NLP6 and 7 are homologous genes to NIN in the model legume Lotus japonicus (52). Nine genes of NIN-like proteins (NLPs) are coded in the Arabidopsis genome (52). NLP7 has the ability to bind to a nitrate-responsive cis-element (28), and regulates the expression of more than 90\% of the primary nitrate-responsive genes in Arabidopsis roots after the application of nitrate (34). Thus, NLP7 is a master regulator of nitrate-responsive genes in Arabidopsis roots (34). TEOSINTE BRANCHED1/CYCLOIDEA/PROLIFERATING CELL FACTOR1-20 (TCP20) is a regulator of nitrate-dependent changes in the root system architecture (19). In order to adapt to the heterogeneous nitrate conditions in natural soils, Arabidopsis elongates the lateral roots in high-nitrate patches, while suppressing elongation in low-nitrate patches (41). This nitrate-dependent systemic modification of lateral roots disappeared in tcp20 mutants (19). Comparisons between tcp 20 mutants and nlp 7 mutants, which are defective in the local control of root growth, but not in the systemic root growth response for nitrate, indicated that TCP20 functions independently of NLP7 (19).

Previous studies investigated root-associated bacterial communities in Arabidopsis (6, 7, 32, 33, 53) and revealed that the community structures of root-associated bacteria are related to soil properties, plant ecotypes $(7,33)$, and salicylic 
acid signaling (32). However, the effects of nitrate on Arabidopsis root-associated bacteria have not yet been clarified.

In the present study, we examined whether plant genes for nitrate signaling are involved in nitrate-dependent community shifts in root-associated bacteria in Arabidopsis. In order to achieve this, root-associated bacterial communities were investigated under various nitrate levels via a ribosomal RNA intergenic spacer analysis (RISA). The bacterial community was determined via $16 \mathrm{~S}$ rRNA amplicon sequencing at the family level. The relative abundance and potential function of root-associated bacteria were then compared between wildtype Arabidopsis and T-DNA insertion lines of the NLP7 and TCP20 genes under low- and high-nitrate conditions.

\section{Materials and Methods}

\section{Soil collection and preparation}

The top $10 \mathrm{~cm}$ of a gray lowland soil was collected with a shovel from an experimental field in Kashimadai, Miyagi, Japan $\left(38^{\circ} 27^{\prime} 39.37^{\prime \prime} \mathrm{N}, 141^{\circ} 5^{\prime} 33.33^{\prime \prime E}\right.$; altitude $\left.4 \mathrm{~m}\right)$ and transported to the laboratory in plastic containers at an ambient temperature (24). The soil was sampled in July 2013 and then air-dried in a greenhouse for $15 \mathrm{~d}$. Visible weeds, twigs, worms, insects, and other organisms were removed from air-dried soil, which was then crushed with a rubber mallet to a fine consistency. The soil was then stored at room temperature in a closed polyethylene bucket until used.

\section{Growth and harvest}

Arabidopsis ecotype Col-0 was used as the wild-type plant for every analysis. Seeds were sterilized in $70 \%$ ethanol before sowing (29). Plants were cultivated in sterilized $10 \times 9 \times 8 \mathrm{~cm}$ plastic containers (Steri Vent high container; Duchefa Biochemie B.V., Amsterdam, the Netherlands), each containing $250 \mathrm{~g}$ of air-dried soil. Five to eight seeds were sown in 5 respective points in each container (four corners and the center) and $100 \mathrm{~mL}$ of pure water was then added. When nitrate was supplied, various $\left(0,60,120,180\right.$, and $240 \mathrm{mg} \mathrm{N} \mathrm{kg}^{-1}$ soil) amounts of sterilized $1 \mathrm{M} \mathrm{KNO}_{3}$ solution were added to the container. Nitrate was only added once: before sowing or 15,20 , or $25 \mathrm{~d}$ after sowing. As shown in Fig. 1B and C, the no nitrate added condition was defined as a low-nitrate (LN) condition, while the $240 \mathrm{mg} \mathrm{N} \mathrm{kg}^{-1}$ nitrate applied condition was defined as a high-nitrate $(\mathrm{HN})$ condition. Five to $7 \mathrm{~d}$ after sowing, the 5 healthiest plants in each container were selected, and the others were removed. A plastic cover was placed loosely on each container for the first $5 \mathrm{~d}$ after sowing to prevent drying, and it was then replaced with a paper cover. Pure water $(30-50 \mathrm{~mL})$ was supplied 10, 15, 20, and $25 \mathrm{~d}$ after sowing. Plants were grown in a culture room $(14 \mathrm{~h} / 10 \mathrm{~h}$ light/ dark cycle, $19-22^{\circ} \mathrm{C}$, and $160 \mu \mathrm{mol} \mathrm{m} \mathrm{m}^{-2} \mathrm{~s}^{-1}$ photosynthetic photon flux density). Containers were rotated on the shelf every $5 \mathrm{~d}$. Plants other than Arabidopsis growing in the containers were removed at these times.

Plants were harvested $30 \mathrm{~d}$ after sowing for every analysis. At the same time, bulk soil $(400-500 \mathrm{mg})$ was collected from places in the container without plants $(5-10 \mathrm{~mm}$ depth from the soil surface). Immediately after cutting the hypocotyl, the shoot fresh weight was measured with an electronic balance (CPA324; Sartorius Co., Göttingen, Germany). The container was then inverted and all soil was placed on a plastic plate in order to allow for the roots to be removed with tweezers. Roots in each container (i.e., those of the five plants) were placed in a clean $50-\mathrm{mL}$ tube containing $25 \mathrm{~mL}$ phosphate buffer (per L: $5.4 \mathrm{~g}$ of $\mathrm{NaH}_{2} \mathrm{PO}_{4}, 8.8 \mathrm{~g}$ of $\mathrm{Na}_{2} \mathrm{HPO}_{4}$, and $200 \mu \mathrm{L}$ of Silwet L-77). Tubes were then vortexed at the maximum speed for $15 \mathrm{~s}$, which released most of the rhizosphere soil from the roots. Root samples included epiphytes and endophytes (33). Water was removed from the roots using a paper towel, the dried roots were placed in a sterile $2-\mathrm{mL}$ tube with zirconia beads (diameter of $5 \mathrm{~mm}$ ) and then immediately frozen at $-80^{\circ} \mathrm{C}$ until used.

\section{Evaluation of soil chemical properties}

Soil $\mathrm{pH}$, total nitrogen, hot water-extracted nitrogen, nitrate, and ammonium contents were assessed by the Tokachi Nokyoren Agricultural Research Institute (Obihiro, Hokkaido, Japan). In the present study, the value of hot water-extracted nitrogen was used as an approximation of available nitrogen.

\section{DNA extraction}

DNA was extracted from root and soil samples using a FastDNA Spin Kit for Soil (MP Biomedicals LLC, Santa Ana, CA, USA) according to the manufacturer's instructions. Root samples were frozen in liquid nitrogen then milled with Tissue Lyser II (Qiagen K. K., Hilden, Germany) at $23 \mathrm{~Hz}$ for $1.5 \mathrm{~min}$. DNA was quantified using a spectrophotometer (NanoDrop 2000; Thermo Fisher Scientific K.K., Waltham, MA, USA), then stored at $-80^{\circ} \mathrm{C}$ until the PCR analysis.

\section{Ribosomal RNA intergenic spacer analysis}

RISA was performed as described by Saito et al. (48) using two primer sets: the bacterial primer for ITSF/ITSReub and the fungal primer for ITS1F/ITS4. ITSF and ITS1F were labeled by 6-carboxyfluorescein-aminohexyl amidite. After electrophoresis, digital fingerprinting images were obtained with a fluorescent scanner (FLA-2000; Fujifilm, Tokyo, Japan). Band patterns were analyzed using FPQuest Software (Bio-Rad, Hercules, CA, USA). A principalcomponent analysis (PCA) was performed using CANOCO (version 4.5 for Windows; Microcomputer Power, Ithaca, NY, USA) with default parameters (except that intersample scaling was used) to generate ordination plots based on the scores of the first two principal components.

\section{$R T-P C R$}

Plants were grown on agarose plates with half-strength Murashige and Skoog medium agar for $25 \mathrm{~d}$. Total RNA was extracted from whole plants using Sepasol-RNA I Super G (Nacalai Tesque, Kyoto, Japan). Reverse transcription and a DNase treatment were performed using a PrimeScript RT Reagent Kit with genomic DNA Eraser (Takara Bio, Otsu, Japan) with $470 \mathrm{ng}$ of total RNA in a $10 \mu \mathrm{L}$ final volume, according to the manufacturer's instructions. Twice-diluted reverse transcription solution was used for the PCR template. Ex Taq (Takara Bio) was used for PCR. TCP20 (19) and UBQ2 (29) were amplified using the above primers and NLP7 using NLP7 RTPCR F (5'-AGCGTGGGAAGACTGAGAAA-3') and NLP7 ${ }^{-}$ RTPCR_R (5'-TTGGGGGAGCGTATAAGTTG-3').

\section{S rRNA amplicon sequencing}

$16 \mathrm{~S}$ rRNA amplicon sequencing was performed as described previously (11). The V4 region of the bacterial and archaeal $16 \mathrm{~S}$ rRNA gene was amplified using a two-step PCR procedure. The following primers were used in the first step: $515 \mathrm{~F}$ (5'-ACACTCTT TCCCTACACGACGCTCTTCCGATCTGTGCCAGCMGCCGC GGTAA-3') and 806R (5'-GTGACTGGAGTTCAGACGTGTGC TCTTCCGATCT-GGACTACHVGGGTWTCTAAT-3'), and eight forward and four reverse primers in the second step: flow cell binding sites (forward; AATGATACGGCGACCACCGAGATCTACAC, reverse; CAAGCAGAAGACGGCATACGAGAT), Illumina indexes (forward; D501-D508, reverse; D703-D706), and the sequencing primer-binding site (forward; ACACTCTTTCCCTACACGACGC, reverse; GTGACTGGAGTTCAGACGTGTG). Ex Taq HS (Takara Bio) was used for first and second PCR. First PCR was performed as follows: initial denaturation at $94^{\circ} \mathrm{C}$ for 2 min followed by 24 cycles of $94^{\circ} \mathrm{C}$ at $30 \mathrm{~s}, 51^{\circ} \mathrm{C}$ for $30 \mathrm{~s}$, and $72^{\circ} \mathrm{C}$ for $30 \mathrm{~s}$, with final extension at $72^{\circ} \mathrm{C}$ for $5 \mathrm{~min}$. The amplification products were purified using an AMPure XP bead (Beckman Coulter, Brea, USA). Second PCR was performed using purified DNA as a template as follows: initial denaturation at $94^{\circ} \mathrm{C}$ for $2 \mathrm{~min}$ followed by 10 cycles of $94^{\circ} \mathrm{C}$ at $30 \mathrm{~s}$, $60^{\circ} \mathrm{C}$ for $30 \mathrm{~s}$, and $72^{\circ} \mathrm{C}$ for $30 \mathrm{~s}$, with final extension at $72^{\circ} \mathrm{C}$ for $5 \mathrm{~min}$. The amplified products were used for sequencing after purification using AMPure XP beads (Beckman Coulter). PCR and 
amplicon sequencing were performed by FASMAC Co. (Kanagawa, Japan) using the Illumina MiSeq platform, following the $2 \times 250 \mathrm{bp}$ paired-end sequencing protocol (Illumina, San Diego, CA, USA). 16S rRNA gene sequences were processed using MacQIIME 1.9.1 (10), and paired-end sequences assembled using the pick de novo otus command. Low-quality reads were filtered using the multiple split_libraries fastq command. Chimeric sequences were remove $\bar{d}$ using USEARCH6.1 software (15). The remaining sequences were clustered into operational taxonomic units (OTUs) at $97 \%$ similarity using the pick_open_reference otus command in the Greengenes reference database version 13.5. Contaminant sequences from the host plant, classified as chloroplasts or mitochondria, were removed. In order to normalize the number of sequences per sample, the random subsampling of 4,724 sequences from each sample was applied for further analyses. Three independent samples were used per genotype and condition. The number of sequences in each sample after filtering is shown in Table S1.

A principal-coordinates analysis $(\mathrm{PCoA})$ was performed on weighted UniFrac distance matrixes. The rarefaction procedure was repeated 100 times to compute the number of OTUs, Shannon's diversity index, and Simpson's index. Functional profiles of the bacterial community were predicted using the PICRUSt program (31) according to the protocol provided online (http://picrust.github.io/picrust/tutorials/ otu_picking.html). Predicted gene functions were summarized based on the KEGG Pathway database (http://www.genome.jp/kegg/ pathway.html). Statistical comparisons were performed using Welch's $t$-test with $P<0.05$ considered to be significant.

\section{Accession numbers}

Raw sequence data were deposited in the NCBI Sequence Read Archive under accession numbers SRR5182883-SRR5182906.

\section{Results}

\section{Nitrate altered root-associated bacterial communities in Arabidopsis}

Plants were treated with different amounts of nitrate $(0,60$, 120,180 , or $240 \mathrm{mg} \mathrm{N} \mathrm{kg} \mathrm{dry} \mathrm{soil}{ }^{-1}$ ), which corresponded to 6 to $24 \mathrm{~kg}$ of nitrogen fertilizer in a 10 a field (38). A low amount of nitrate $\left(60\right.$ or $120 \mathrm{mg} \mathrm{N} \mathrm{kg}^{-1}$ ) promoted better shoot growth than high-nitrate (180 and $240 \mathrm{mg} \mathrm{N} \mathrm{kg}^{-1}$ ) conditions (Fig. 1A). RISA and subsequent PCA showed no significant differences in root-associated bacterial communities between the 0 and $60 \mathrm{mg} \mathrm{N} \mathrm{kg}^{-1}$ treatments (Fig. 1B, and $\mathrm{C}$ ), whereas community differences were observed between the 120,180 , and $240 \mathrm{mg} \mathrm{N} \mathrm{kg}^{-1}$ treatments and the treatment that received no nitrate. The community shift became more prominent as the nitrate amount increased. Since the most notable difference in RISA profiles was observed between the 0 and $240 \mathrm{mg} \mathrm{N} \mathrm{kg}{ }^{-1}$ treatments, these conditions were defined as low-(LN) and high-nitrate (HN) conditions, respectively. (Note that the nitrate concentration of LN soil was $3.1 \mathrm{mg} \mathrm{N} \mathrm{kg}^{-1}$ after planting [Table 1].)

We then examined the effects of nitrate supply timing on root-associated bacterial communities. The communities were not affected $5 \mathrm{~d}$ after the nitrate treatment, whereas distinct communities were found $10 \mathrm{~d}$ or more after the nitrate treatment (Fig. 1D and E). Community shifts were more prominent with increases in time after the application of nitrate than after the no nitrate treatment (Fig. 1E).

Soil $\mathrm{pH}$ and total nitrogen, available nitrogen, nitrate, and ammonium contents were also assessed, and revealed significant increases in total nitrogen and nitrate contents in $\mathrm{HN}$ soil
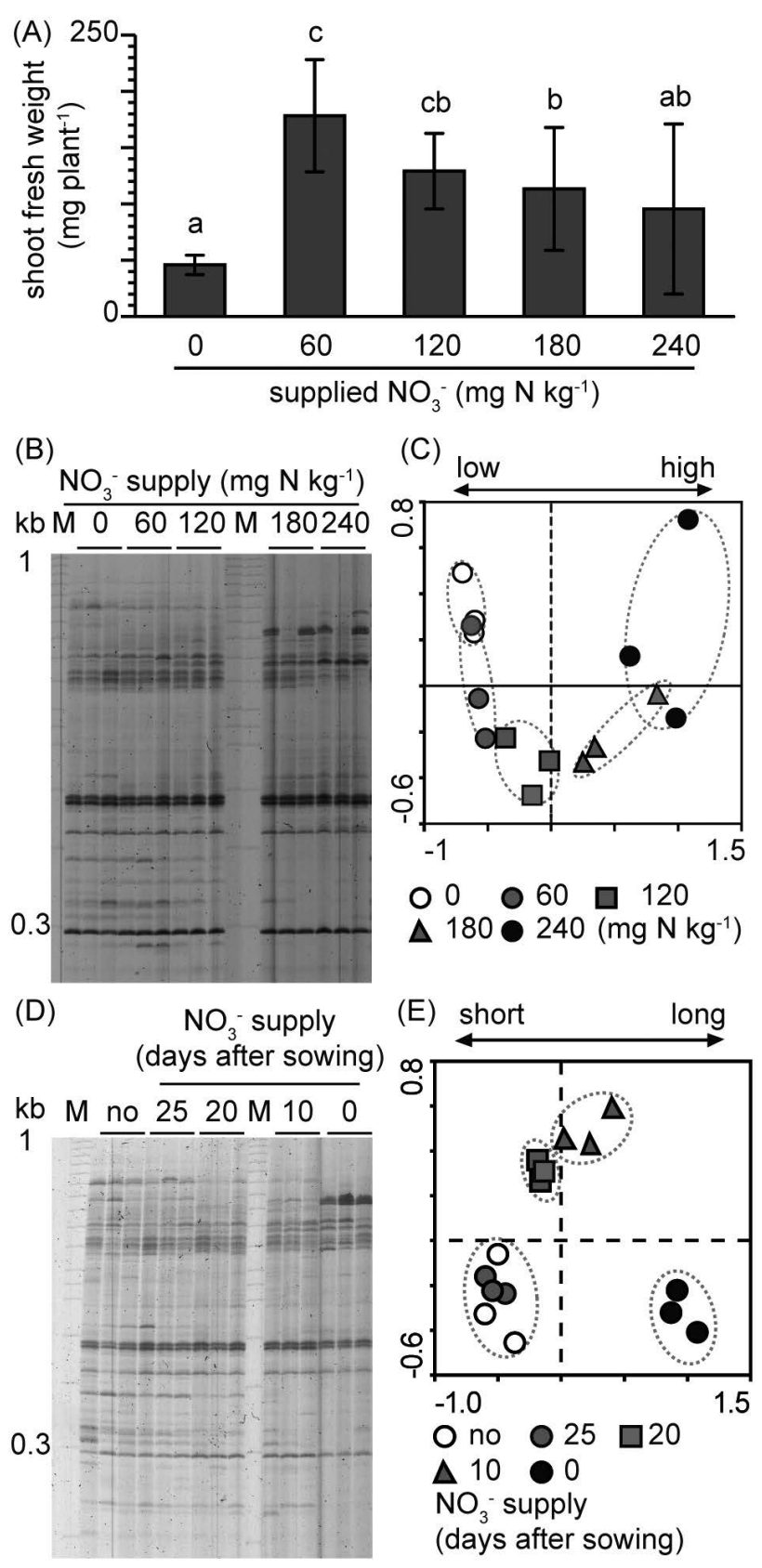

Fig. 1. RISA profiles of nitrate-dependent shifts in Arabidopsis root-associated bacterial communities. (A) Nitrate amount-dependent shoot growth. Data are calculated as means \pm standard deviation $(n=15)$. (B) RISA profiles of nitrate amount-dependent shifts in root-associated bacterial communities. (C) PCA of data in (B); PC1 explained $38.5 \%$ of the variability and PC2 explained $10.8 \%$. (D) RISA profiles of nitrate application timing-dependent shifts in root-associated bacterial communities. Nitrate $\left(240 \mathrm{mg} \mathrm{N} \mathrm{kg}^{-1}\right)$ was added only once, either before sowing or 15,20 , or $25 \mathrm{~d}$ after sowing. (E) PCA of data in (D); PC1 explained $31.1 \%$ of the variability and PC2 explained $12.1 \%$. Plants were grown under various nitrate conditions for $30 \mathrm{~d}$.

$(P<0.05)$. In contrast, lower nitrate and significantly higher ammonium contents were observed in $\mathrm{LN}$ soil $(P<0.05)$ than in unplanted soil (Table 1). The pH of HN soil was significantly less $(P<0.05)$, whereas that of $\mathrm{LN}$ soil was significantly higher $(P<0.05)$ than that of unplanted soil. No significant differences were observed in the amounts of available nitrogen between the soils. 
Table 1. Characteristics of soil used in the present study

\begin{tabular}{cccccc}
\hline & soil pH & $\begin{array}{c}\text { total nitrogen } \\
(\%)\end{array}$ & $\begin{array}{c}\text { available nitrogen } \\
\left(\mathrm{mg} \mathrm{kg}^{-1}\right)\end{array}$ & $\begin{array}{c}\text { nitrate } \\
\left(\mathrm{mg} \mathrm{kg}^{-1}\right)\end{array}$ & $\begin{array}{c}\text { ammonium } \\
\left(\mathrm{mg} \mathrm{kg}^{-1}\right)\end{array}$ \\
\hline $\begin{array}{c}\text { Not planted } \\
\text { At harvest }\end{array}$ & $5.73 \pm 0.06^{\mathrm{b}}$ & $0.12 \pm 0.00^{\mathrm{a}}$ & $29.3 \pm 1.0^{\mathrm{a}}$ & $5.9 \pm 0.3^{\mathrm{b}}$ & $10.5 \pm 1.2^{\mathrm{a}}$ \\
LN & $5.97 \pm 0.06^{\mathrm{a}}$ & $0.12 \pm 0.01^{\mathrm{ab}}$ & $28.0 \pm 3.2^{\mathrm{a}}$ & $3.1 \pm 0.6^{\mathrm{a}}$ & $15.7 \pm 0.8^{\mathrm{b}}$ \\
HN & $5.17 \pm 0.06^{\mathrm{c}}$ & $0.14 \pm 0.01^{\mathrm{b}}$ & $30.6 \pm 0.7^{\mathrm{a}}$ & $210.1 \pm 5.7^{\mathrm{c}}$ & $11.9 \pm 2.4^{\mathrm{ab}}$ \\
\hline
\end{tabular}

LN, no nitrate application; $\mathrm{HN}$, high $\left(240 \mathrm{mg} \mathrm{N} \mathrm{kg}^{-1}\right)$ nitrate application. Values represent means \pm standard deviation $(n=3)$. Within each column, different letters indicate significant differences at $P<0.05$ according to Welch's $t$-test.

\section{Nitrate-responsive bacteria in Arabidopsis roots}

In order to identify the bacterial groups for which abundance was affected by the nitrate supply, root-associated bacterial communities were analyzed using 16S rRNA amplicon sequencing under LN and HN conditions. Bacterial communities in bulk soil samples were also examined in order to clarify the effects of nitrate on free-living bacterial communities. According to PCoA plots, root-associated bacterial communities were different from those in bulk soil, as explained by PC1 (Fig. 2A). Nitrate-dependent shifts in root-associated bacterial communities were also observed by $16 \mathrm{~S}$ rRNA amplicon sequencing (Fig. 2A and B). Bacterial communities in bulk soil appeared to differ between the LN and HN conditions; however, the community shift was smaller than that of root-associated bacteria. The bacterial community shift in bulk soil was observed along the PC3 axis, whereas that of roots was observed along the PC2 axis.

Amplicon sequencing produced 423 OTUs, each of which contained at least five reads in the root samples. The relative abundance of OTUs of $25.8 \%$ was changed by the application of nitrate; $18.2 \%$ of the OTUs were decreased by nitrate, whereas $7.6 \%$ were increased $(P<0.05$, Fig. $2 \mathrm{C})$. The indexes of alpha diversity (Shannon's, Simpson's, and number of OTUs) in wild-type roots were decreased by the application of nitrate ( $P<0.05$, Fig. 2D-F). Proteobacteria, Bacteroidetes, and Firmicutes were the major phyla of root-associated bacteria for which relative abundance was altered (Table 2) and all are major phyla in Arabidopsis roots $(6,7,33)$. The most abundant families (more than $5 \%$ of the average relative abundance) are shown in Table 3. The relative abundance of Burkholderiaceae and Paenibacillaceae increased by more than 100-fold with the application of nitrate, whereas that of Comamonadaceae, Caulobacteraceae, Sphingomonadaceae, Bradyrhizobiaceae, Rhizobiaceae, Chitinophagaceae, and Cytophagaceae decreased $(P<0.05)$.

\section{Effects of NLP7 and TCP20 genes on root-associated bacte- rial communities}

Four independent T-DNA insertion lines for NLP7 (nlp 7-1 and $n l p 7-2)$ and TCP2O (tcp20-2 and tcp20-4) were obtained from the Arabidopsis Biological Resource Center using Col-0 as the genetic background. Previously, $n l p 7-1$ and $n l p 7-2$ were identified as knockout and knockdown mutants, respectively (12), and tcp20-2 and tcp20-4 as knockout mutants (19). An RT-PCR analysis showed that NLP7 or TCP20 gene expression disappeared due to the respective T-DNA insertion (Fig. $\mathrm{S} 1$ ). Moreover, the expression levels of $N L P 7$ were so low in $n l p 7-2$ that they were not detectable by our RT-PCR.
(A)

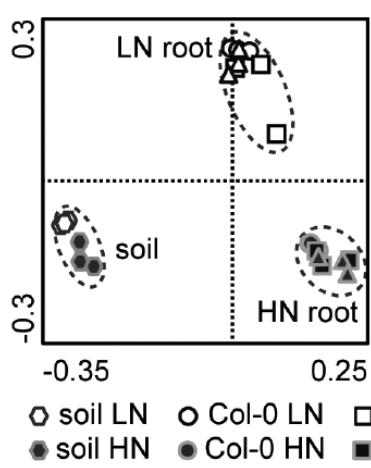

(C)

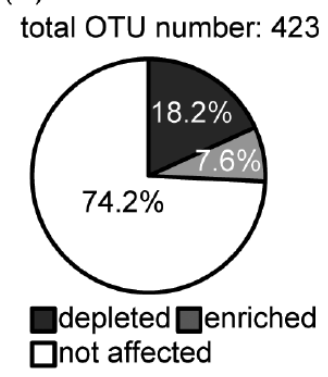

(E)

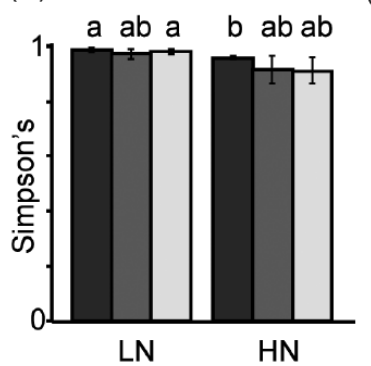

(F)

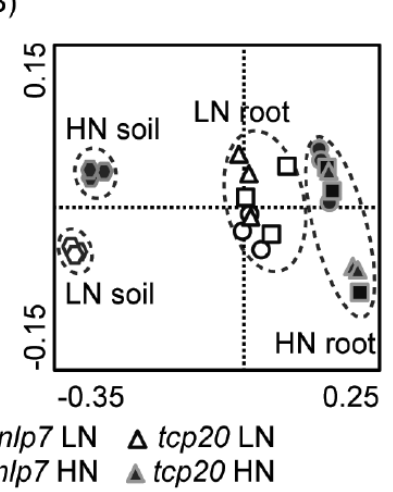

(D)
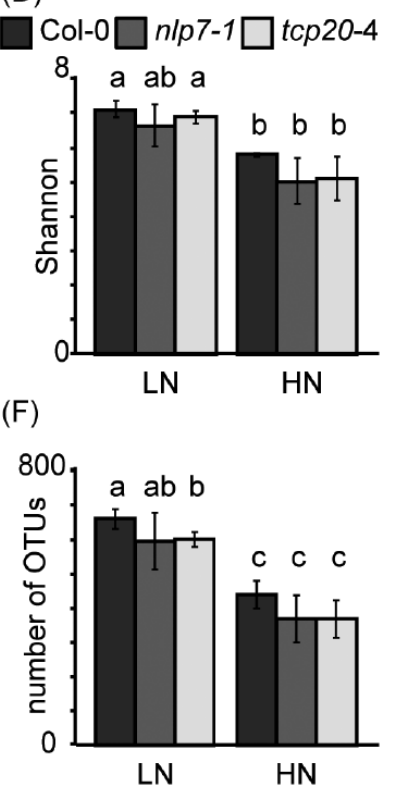

Fig. 2. PCoA plots for $16 \mathrm{~S}$ rRNA genes of bacteria associated with wild-type Arabidopsis, nlp7-1, and tcp20-4 roots and those in bulk soil. (A) PC1 vs. PC2 plot; PC1 explained $45.2 \%$ of the variability and PC2 explained $38.0 \%$. (B) PC1 vs. PC3 plot; PC3 explained $6.8 \%$ of the variability. Low-nitrate (LN) conditions were indicated by open symbols and high-nitrate (HN) conditions were indicated by closed symbols. The ordination was constructed using UniFrac distances. (C) The percentage of nitrate-affected OTUs in wild-type (Col-0) roots. The relative abundance of OTUs in wild-type roots of the LN treatment was compared with that of HN. (D) Shannon's diversity index, (E) Simpson's diversity index, and $(\mathrm{F})$ the number of OTUs; different letters indicate significant differences $(P<0.05)$ between bars, according to Welch's $t$-test. Data represent means \pm standard deviation $(n=3)$. LN, no nitrate application; $\mathrm{HN}$, high (240 $\mathrm{mg} \mathrm{N} \mathrm{kg}^{-1}$ ) nitrate application.

The community structures of root-associated bacteria were compared between wild-type and insertion lines (nlp7-2 and tcp 20-2) using RISA (Fig. 3A). In PCA plots, the bacterial 
Table 2. The relative abundance of $16 \mathrm{~S}$ rRNA genes of bacteria associated with roots of wild-type Arabidopsis and nlp 7-1 and tcp 20-4 mutants at the phylum, class, and order levels.

\begin{tabular}{|c|c|c|c|c|c|c|}
\hline \multirow{2}{*}{ Taxon } & \multicolumn{3}{|c|}{$\mathrm{LN}$} & \multicolumn{3}{|c|}{$\mathrm{HN}$} \\
\hline & Col-0 & $n l p 7-1$ & tcp20-4 & Col-0 & $n l p 7-1$ & tсp20-4 \\
\hline Proteobacteria & 54.5 & 57.6 & 51.0 & 59.8 & 69.3 & 72.8 \\
\hline Alphaproteobacteria & 6.2 & 6.3 & 6.5 & 3.0 & $2.0^{*}$ & 2.4 \\
\hline Rhizobiales & 3.7 & 3.4 & 3.4 & 0.9 & 0.7 & 0.9 \\
\hline Caulobacterales & 1.5 & 1.7 & 1.6 & 0.8 & 0.6 & 0.7 \\
\hline Sphingomonadales ${ }^{\#}$ & 0.7 & 0.9 & $1.2 *$ & 1.0 & $0.6^{*}$ & 0.7 \\
\hline Betaproteobacteria & 36.6 & 43.0 & 33.3 & 49.7 & 63.3 & 64.9 \\
\hline Burkholderiales & 26.2 & 34.8 & 25.9 & 48.9 & 62.8 & 64.6 \\
\hline Rhodocyclales & 9.5 & 7.4 & 6.7 & 0.2 & 0.0 & 0.0 \\
\hline Deltaproteobacteria\# & 7.3 & 5.5 & 6.9 & 0.5 & 0.3 & 0.3 \\
\hline Myxococcales & 5.6 & 4.2 & 5.5 & 0.2 & 0.1 & 0.1 \\
\hline Gammaproteobacteria & 4.4 & 2.8 & 4.2 & 6.6 & 3.8 & 5.2 \\
\hline Legionellales & 2.2 & 1.0 & 2.0 & 0.6 & 0.3 & 0.4 \\
\hline Xanthomonadales & 2.0 & 1.6 & 2.0 & 5.8 & 3.3 & 4.6 \\
\hline Actinobacteria & 6.8 & 13.3 & 17.0 & 10.9 & 7.5 & 6.1 \\
\hline Actinobacteria & 6.6 & 13.0 & 16.7 & 10.7 & 7.4 & 5.9 \\
\hline Bacteroidetes $^{\#}$ & 13.8 & 12.7 & 13.4 & 4.0 & 3.1 & 2.0 \\
\hline Saprospirae $\#$ & 7.5 & 7.4 & 8.3 & 3.2 & 2.2 & $1.1^{*}$ \\
\hline Cytophagia & 4.3 & 3.8 & 3.6 & 0.4 & 0.7 & 0.7 \\
\hline Sphingobacteriia & 2.0 & 1.5 & 1.5 & 0.5 & 0.2 & 0.1 \\
\hline Firmicutes ${ }^{\#}$ & 0.2 & 0.4 & 0.3 & 9.9 & 6.1 & 5.6 \\
\hline Bacilli $^{\#}$ & 0.2 & 0.4 & $0.3^{*}$ & 9.9 & 6.0 & 5.5 \\
\hline Chloroflexi & 5.9 & 3.7 & 5.1 & 1.8 & 0.9 & 1.3 \\
\hline Ktedonobacteria & 3.7 & 2.1 & 3.1 & 1.6 & 0.8 & 1.2 \\
\hline Verrucomicrobia & 1.8 & 1.9 & 1.3 & 0.1 & 0.1 & 0.1 \\
\hline Acidobacteria $\#$ & 0.9 & 0.7 & 0.8 & 0.2 & 0.2 & 0.1 \\
\hline Other & 16.1 & 9.8 & 11.2 & 13.4 & 12.7 & 12.0 \\
\hline
\end{tabular}

\# indicates a significant difference $(P<0.05)$ between low- $(\mathrm{LN})$ and high-nitrate $(\mathrm{HN})$ conditions in the wild-type $(\mathrm{Col}-0) . *$ indicates a significant difference $(P<0.05)$ between the wild-type and $n l p 7-1$ or $t c p 20-4$ according to Welch's $t$-test. LN, no nitrate application; HN, high $\left(240 \mathrm{mg} \mathrm{N} \mathrm{kg}^{-1}\right)$ nitrate supply. Values represent means $(n=3)$.

Table 3. The relative abundance of $16 \mathrm{~S}$ rRNA genes of major bacteria associated with roots of wild-type Arabidopsis at the family level.

\begin{tabular}{|c|c|c|c|c|c|}
\hline Taxon & $\begin{array}{l}\mathrm{LN} \\
(\%) \\
\end{array}$ & $\begin{array}{l}\mathrm{HN} \\
(\%)\end{array}$ & $\begin{array}{c}\mathrm{LN}+\mathrm{HN} \\
(\%)\end{array}$ & $\mathrm{P}$ value & $\begin{array}{l}\text { Fold change } \\
(\mathrm{HN} / \mathrm{LN})\end{array}$ \\
\hline Betaproteobacteria Oxalobacteraceae & 13.89 & 24.03 & 18.96 & 0.068 & 1.731 \\
\hline Unassigned & 12.50 & 6.73 & 9.61 & 0.080 & 0.539 \\
\hline Betaproteobacteria Burkholderiaceae $e^{\#}$ & 0.05 & 13.53 & 6.79 & 0.040 & 274 \\
\hline Betaproteobacteria Comamonadaceae & 11.69 & 1.02 & 6.36 & 0.015 & 0.088 \\
\hline Actinobacteria Streptomycetaceae & 4.73 & 7.33 & 6.03 & 0.222 & 1.551 \\
\hline Bacteroidetes Chitinophagaceae & 7.49 & 3.16 & 5.33 & 0.003 & 0.422 \\
\hline Betaproteobacteria Burkholderiales Unassigned ${ }^{\#}$ & 0.21 & 10.29 & 5.25 & 0.006 & 48.6 \\
\hline Betaproteobacteria Rhodocyclaceae & 9.54 & 0.21 & 4.88 & 0.073 & 0.022 \\
\hline Firmicutes Paenibacillaceae & 0.09 & 9.50 & 4.80 & 0.022 & 103.615 \\
\hline Gammaproteobacteria Xanthomonadaceae & 1.58 & 5.76 & 3.67 & 0.061 & 3.647 \\
\hline Chloroflexi Ktedonobacteraceae & 3.66 & 1.57 & 2.61 & 0.064 & 0.429 \\
\hline Cyanobacteria SM1D11 Unassigned & 0.24 & 4.59 & 2.41 & 0.053 & 19.118 \\
\hline Deltaproteobacteria Myxococcales Unassigned\# & 3.81 & 0.13 & 1.97 & 0.002 & 0.035 \\
\hline Bacteroidetes Cytophagaceae & 3.02 & 0.32 & 1.67 & 0.030 & 0.105 \\
\hline Alphaproteobacteria Caulobacteraceae & 1.50 & 0.82 & 1.16 & 0.010 & 0.545 \\
\hline Gammaproteobacteria Legionellales Unassigned & 1.57 & 0.35 & 0.96 & 0.104 & 0.225 \\
\hline Alphaproteobacteria Sphingomonadaceae & 0.66 & 0.93 & 0.79 & 0.036 & 1.419 \\
\hline Alphaproteobacteria Bradyrhizobiaceae & 1.40 & 0.13 & 0.77 & 0.002 & 0.095 \\
\hline Alphaproteobacteria Rhizobiaceae & 1.46 & 0.06 & 0.76 & 0.013 & 0.043 \\
\hline Verrucomicrobia Opitutaceae & 1.33 & 0.03 & 0.68 & 0.026 & 0.021 \\
\hline Bacteroidetes Sphingobacteriales Unassigned" & 1.28 & 0.06 & 0.67 & 0.050 & 0.044 \\
\hline Actinobacteria Nocardiaceae & 0.42 & 0.88 & 0.65 & 0.251 & 2.119 \\
\hline Bacteroidetes Cytophagales Unassigned ${ }^{\#}$ & 1.24 & 0.04 & 0.64 & 0.003 & 0.034 \\
\hline Actinobacteria Actinomycetales Unassigned & 0.18 & 1.09 & 0.63 & 0.193 & 6.16 \\
\hline Bacteroidetes Sphingobacteriaceae & 0.73 & 0.40 & 0.56 & 0.245 & 0.553 \\
\hline Actinobacteria Micromonosporaceae & 0.87 & 0.23 & 0.55 & 0.047 & 0.258 \\
\hline Chloroflexi ouleothrixaceae & 1.07 & 0.02 & 0.54 & 0.011 & 0.020 \\
\hline Deltaproteobacteria Haliangiaceae $\#$ & 0.99 & 0.02 & 0.51 & 0.049 & 0.021 \\
\hline
\end{tabular}

\# indicates a significant difference $(P<0.05)$ between low nitrate $(\mathrm{LN})$ and high nitrate $(\mathrm{HN})$ in the wild-type $(\mathrm{Col}-0)$ according to Welch's $t$-test. LN, no nitrate application; HN, high $\left(240 \mathrm{mg} \mathrm{N} \mathrm{kg}^{-1}\right)$ nitrate supply. Values represent means $(n=3)$. 


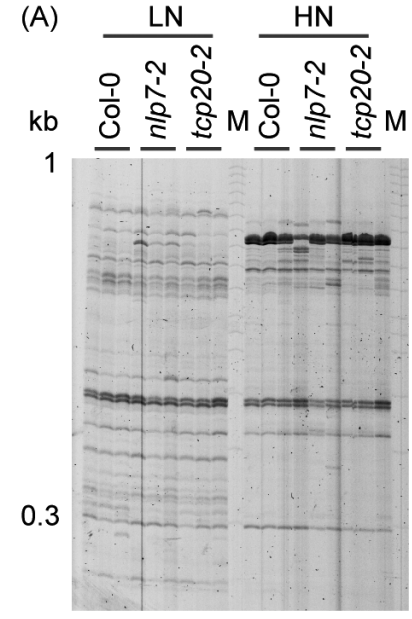

(B)

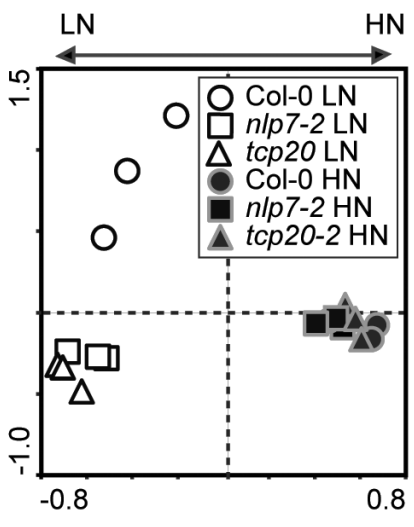

(C)

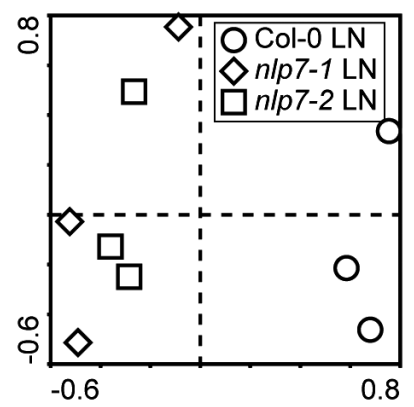

(D)

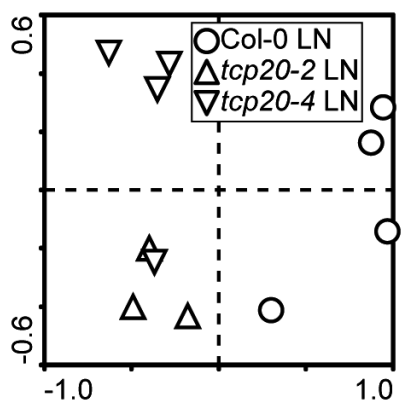

Fig. 3. RISA profiles of root-associated bacterial communities in Arabidopsis wild-type (Col-0) and $n l p 7$ and tcp 20 mutants. (A) RISA profiles of root-associated bacterial communities in the wild-type, $n l p 7-2$, and tcp 20-2 under low-nitrate (LN) and high-nitrate (HN) conditions. (B) PCA of the data in (A); PC1 explained $31.7 \%$ of the variability and PC2 explained $17.7 \%$. (C) PCA of the RISA bacterial profile of the wild-type, $n l p 7-1$, and $n l p 7-2$ under LN conditions; PC1 explained $24.2 \%$ of the variability and PC2 explained $17.0 \%$. (D) PCA of RISA bacterial profile of the wild-type, $t c p 20-2$, and $t c p 20-4$ under LN conditions; PC1 explained $33.3 \%$ of the variability and PC2 explained $10.8 \%$. LN: No nitrate application, $\mathrm{HN}$ : Nitrate $\left(240 \mathrm{mg} \mathrm{N} \mathrm{kg}^{-1}\right)$ application. communities of insertion lines differed from those of the wild-type under LN conditions, but not under $\mathrm{HN}$ conditions (Fig. 3B). Similar differences were observed in the second insertion lines for the NLP7 (Fig. 3C) and TCP2O (Fig. 3D) genes under LN conditions. Fungus-specific RISA profiles showed only one band in all genotypes, and the fungus signal was not affected by nitrate application (Fig. S2).

In order to identify the bacterial groups for which abundance was affected by the knockout of the NLP7 or TCP2O gene, bacterial communities were analyzed by $16 \mathrm{~S}$ rRNA amplicon sequencing in the roots of the wild-type and two insertion lines (nlp 7-1 and tcp20-4). The PCoA plots did not show significant differences in bacterial communities between the wild-type and two insertion lines under $\mathrm{LN}$ or $\mathrm{HN}$ conditions (Fig. 2A and B). The number of OTUs in tcp20-4 was lower in $\mathrm{LN}$ than in the wild-type $(P<0.05$, Fig. $2 \mathrm{~F})$, whereas no significant differences were observed in Shannon's and Simpson's indexes (Fig. 2D and E). In $n l p 7-1$, these indexes were similar to those of the wild-type (Fig. 2D-F). Although PCoA plots did not show clear community differences between the wild-type and two insertion lines by 16S rRNA sequencing, a phylogenetic analysis showed significant differences in several minor taxonomic groups. The lack of NLP7 and TCP20 significantly affected the relative abundance of 4 classes, 13 families, 20 genera, and 48 OTUs (Table 2, 4, S2, and S3). Under LN conditions, the abundance of Sphinogomonadaceae, Actinomycetales, and Norcardiodaceae increased in tcp20-4, while that of Bacteriovoracaceae decreased in nip7-1 (Table 4). In contrast, under HN conditions, the abundance of Alphaproteobacteria, including Sphingomonadaceae, decreased in nlp7-1, while that of Chitinophagaceae, Nocardioidaceae, and Micrococcaceae decreased in tcp20-4 (Table 2 and 4). These results suggest that NLP7 and TCP20 affect the interaction with certain minor root-associated bacteria in Arabidopsis.

Table 4. The relative abundance of $16 \mathrm{~S}$ rRNA genes of bacterial families associated with roots of wild-type Arabidopsis and nlp7-1 and tcp 20-4 mutants.

\begin{tabular}{|c|c|c|c|c|c|c|}
\hline \multirow{2}{*}{ Taxon } & \multicolumn{3}{|c|}{$\mathrm{LN}$} & \multicolumn{3}{|c|}{$\mathrm{HN}$} \\
\hline & Col-0 & nlp7-1 & tcp20-4 & Col-0 & nlp 7-1 & tcp20-4 \\
\hline Proteobacteria & & & & & & \\
\hline Sphingomonadaceae & 0.66 & 0.89 & $1.23 *$ & 0.93 & $0.61 *$ & 0.56 \\
\hline Hyphomicrobiaceae & 0.31 & 0.24 & $0.16^{*}$ & 0.52 & 0.44 & 0.61 \\
\hline Bacteriovoracaceae & 0.15 & $0.07 *$ & $0.04 *$ & 0.01 & 0.00 & 0.00 \\
\hline Myхососсасеае & 0.06 & 0.01 & $0.03 *$ & 0.01 & 0.00 & 0.00 \\
\hline $\begin{array}{l}\text { Legionellales_unclassified } \\
\text { Actinobacteria }\end{array}$ & 1.57 & 0.54 & 1.32 & 0.35 & $0.16^{*}$ & 0.26 \\
\hline Actinomycetales unclassified & 0.18 & 0.23 & $0.37 *$ & 1.09 & 0.42 & 0.71 \\
\hline Nocardioidaceae & 0.17 & 0.23 & $0.40^{*}$ & 0.20 & 0.13 & $0.11^{*}$ \\
\hline Micrococcaceae & 0.04 & 0.06 & 0.06 & 0.16 & 0.06 & $0.08^{*}$ \\
\hline $\begin{array}{l}\text { Bacteroidetes } \\
\text { Chitinophagaceae } \\
\text { Others }\end{array}$ & 7.49 & 7.39 & 8.35 & 3.16 & 2.24 & $1.14 *$ \\
\hline Chthonomonadaceae & 0.05 & $0.01 *$ & 0.04 & 0.01 & 0.00 & 0.00 \\
\hline Parachlamydiaceae $^{\#}$ & 0.23 & $0.05 *$ & 0.20 & 0.05 & 0.03 & 0.05 \\
\hline Clostridiaceae & 0.03 & 0.01 & 0.01 & 0.01 & 0.04 & $0.04 *$ \\
\hline
\end{tabular}

\# indicates a significant difference $(P<0.05)$ between low nitrate $(\mathrm{LN})$ and high nitrate $(\mathrm{HN})$ in the wild-type $(\mathrm{Col}-0)$. * indicates a significant difference $(P<0.05)$ between the wild-type and $n l p 7-1$ or tcp 20-4 according to Welch's $t$-test. LN, no nitrate application; HN, high (240 $\left.\mathrm{mg} \mathrm{N} \mathrm{kg}^{-1}\right)$ nitrate supply. Values represent means $(n=3)$. 
Effects of NLP7 and TCP20 on functional genes in rootassociated bacterial communities

In order to examine the knockout effects of the NLP7 or $T C P 20$ gene on bacterial functions, functional gene frequencies were estimated from 16S rRNA sequencing and the gene contents of known bacterial genomes using PICRUSt (31). These genes were classified by functional units in the KEGG pathway for each nitrate condition. Under LN conditions, tcp 20-4 showed more than 40 differences in metabolic pathways from the wild-type, whereas $n l p 7-1$ showed only several differences (Table S4). The lack of TCP20 under LN conditions affected the pathways of secondary metabolism, lipid metabolism, xenobiotic biodegradation and metabolism, cellular processes, environmental information processing, and others (Table S4). Under HN conditions, the lack of NLP7 affected many pathways, including secondary metabolism, amino acid metabolism, carbohydrate metabolism, lipid metabolism, xenobiotic biodegradation and metabolism, and environmental information processing, whereas the lack of TCP20 showed only a few minor differences (Table 5). These results indicate that the knockout of the NLP7 or TCP20 gene affects some functions of the root-associated bacterial community.

\section{Discussion}

The present study is the first to examine nitrate-dependent shifts in bacterial communities associated with Arabidopsis roots. Robinson et al. (42) proposed that fertilizer-dependent alterations in root-associated bacteria were regulated by two processes. Fertilizers may directly alter soil bacterial communities and, hence, affect the available pool from which bacteria colonize the plant. Furthermore, fertilizers may alter plant traits, such as growth and exudate production, thereby affecting the recruitment of endophytic communities. In the present study, root-associated bacterial communities were clearly different from those of bulk soil, and presented more significant community shifts $30 \mathrm{~d}$ after nitrate application (Fig. 2A and $\mathrm{B}$ ). These results suggest that nitrate-dependent alterations in root-associated bacteria are mainly affected by plant-derived factors at least in Arabidopsis roots.

In the present study, the relative abundance of Burkholderiaceae and Paenibacillaceae increased by more than 100-fold with nitrate application (Table 3). Several members of Burkholderiaceae (26) and Paenibacillaceae $(46,47)$ have been suggested to compose the major groups of plant growth-promoting bacteria. For example, in rice roots, Burkholderia kururiensis KP23T contributes to nitrogen acquisition via nitrogen fixing functions in low nitrogen environments (26). However, the physiological implications of the interaction with Burkholderiaceae may differ between Arabidopsis and rice because the abundance of Burkholderiaceae decreases with the application of nitrogen in rice roots (26). Since a closed container was used in our cultivation system, soil was expected to be anaerobic, at least immediately after water supply. Under anaerobic conditions, Burkholderiaceae bacteria can reduce the nitrate (60). Since nitrate reduction is a highly energy-demanding process during nitrogen assimilation in plants (20), Burkholderiaceae may contribute to nitrate utilization in Arabidopsis roots through nitrate reduction.
Members of Paenibacillaceae reportedly function as biocontrol agents for phytopathogens $(46,47)$ and also reduce biotic stress under high nitrate conditions $(46,47)$. Therefore, further analyses of the physiological effects of these nitrate-induced bacteria on Arabidopsis growth under high nitrate conditions are required.

Previous studies investigated nitrogen-dependent alterations in relationships with root-associated bacteria using high-resolution analyses, such as $16 \mathrm{~S}$ rRNA amplicon sequencing and metagenome analyses $(26,42,60)$. Reductions in Alphaproteobacteria by certain environmental factors are commonly observed in the roots of rice, wheat, sugarcane, and Arabidopsis (Table 2 and 3) $(26,42,60)$, although the cultivation conditions and nitrogen forms supplied differed. Bradyrhizobiaceae and Rhizobiaceae include several nitrogen-fixing bacteria. The abundance of nitrogen-fixing Alphaproteobacteria was also found to decrease in the roots of rice (26) and legumes (40) with the application of nitrogen. Therefore, the mechanisms underlying nitrogen-dependent reductions in Alphaproteobacteria in roots appear to be conserved among higher plants.

In rice roots, the Calcium/Calmodulin-Dependent Protein Kinase $(C C a M K)$ gene regulates the abundance of rootassociated Alphaproteobacteria (25) and interactions with methanotrophs and nitrogen-fixing bacteria $(4,36)$. CCaMK is also an essential gene in the common symbiotic signaling pathway (CSP), which is necessary for developing a symbiotic relationship with rhizobia and mycorrhizal fungi in legumes (36). CSP is conserved in grasses, but not in Arabidopsis (62). We observed nitrate-dependent reductions in the relative abundance of Alphaproteobacteria in Arabidopsis roots (Table 2), suggesting that the interaction with Alphaproteobacteria is partially altered by a CSP-independent pathway. The CSPindependent regulation of endophytic Alphaproteobacteria has also been reported in rice (13).

$N L P$ (52) and TCP (35) homologous genes are wellconserved transcription factors in higher plants, working independently of CSP. In the present study, the knockout of these genes significantly affected the abundance of several minor bacteria as well as a number of bacterial functions (Table 2, 4, 5, S2, S3, and S4). More than 80 functional pathways including amino acid, carbohydrate, lipid, and secondary metabolism were changed in the roots of the $n l p 7$ mutant under nitrate application (Table 5). In contrast, tcp20 mutants showed several minor differences under LN conditions including alterations in root-associated bacterial communities (Fig. 3), bacterial relative abundance (Table 2, 4, S2, and S3), and functional gene frequencies (Table S4). However, these knockouts did not affect nitrate-dependent community shifts in root-associated bacteria (Fig. 2 and 3), suggesting that NLP7 and TCP20 are not the major regulators of nitrate-dependent alterations in root-associated bacteria.

The present study aimed to demonstrate the relationship between plant genes for nitrate signaling and nitrate-dependent community shifts in root-associated bacteria. However, this relationship remains unclear because the knockout of NLP7 and TCP20 did not exert strong effects on nitrate-dependent community shifts (Fig. 2). Nevertheless, nitrate-dependent shifts in bacterial communities in the roots of Arabidopsis strongly suggest the existence of plant regulator(s) of rootassociated bacteria, which warrants further study. 
Table 5. Comparison of bacterial functional gene frequencies in roots of wild-type Arabidopsis with those of $n l p 7-1$ and tcp 20-4 mutants under high-nitrate (HN) conditions

\begin{tabular}{|c|c|c|c|}
\hline \multirow{2}{*}{ KEGG pathway } & \multicolumn{3}{|c|}{ Gene frequency $(\mathrm{HN})$} \\
\hline & Col-0 & $n l p 7-1$ & tcp20-4 \\
\hline \multicolumn{4}{|l|}{ Metabolism } \\
\hline \multicolumn{4}{|l|}{ Amino Acid Metabolism } \\
\hline Lysine degradation & 0.377 & $0.102 *$ & 0.291 \\
\hline Phenylalanine metabolism & 0.299 & $0.081 *$ & 0.228 \\
\hline Tryptophan metabolism & 0.495 & $0.132 *$ & 0.379 \\
\hline Valine, leucine, and isoleucine biosynthesis & 0.475 & $0.130 *$ & 0.371 \\
\hline Valine, leucine, and isoleucine degradation & 0.721 & $0.202 *$ & 0.559 \\
\hline beta-Alanine metabolism & 0.379 & $0.103 *$ & 0.299 \\
\hline Cyanoamino acid metabolism & 0.188 & $0.049 *$ & 0.139 \\
\hline D-Alanine metabolism & 0.061 & $0.016^{*}$ & 0.045 \\
\hline Selenocompound metabolism & 0.270 & $0.069 *$ & 0.205 \\
\hline \multicolumn{4}{|l|}{ Biosynthesis of Other Secondary Metabolites } \\
\hline Butirosin and neomycin biosynthesis & 0.031 & $0.009 *$ & 0.020 \\
\hline Penicillin and cephalosporin biosynthesis & 0.093 & $0.022 *$ & 0.069 \\
\hline Phenylpropanoid biosynthesis & 0.064 & $0.019 *$ & 0.038 \\
\hline Streptomycin biosynthesis & 0.203 & $0.051 *$ & 0.147 \\
\hline \multirow{2}{*}{\multicolumn{4}{|c|}{ Carbohydrate Metabolism }} \\
\hline & & & \\
\hline Amino sugar and nucleotide sugar metabolism & 0.746 & $0.194 *$ & 0.570 \\
\hline Ascorbate and aldarate metabolism & 0.147 & $0.035^{*}$ & 0.103 \\
\hline Butanoate metabolism & 0.826 & $0.228 *$ & 0.657 \\
\hline Citrate cycle (TCA cycle) & 0.520 & $0.144 *$ & 0.409 \\
\hline Fructose and mannose metabolism & 0.300 & $0.081^{*}$ & 0.231 \\
\hline Galactose metabolism & 0.312 & $0.082 *$ & 0.222 \\
\hline Glycolysis/Gluconeogenesis & 0.698 & $0.185^{*}$ & 0.539 \\
\hline Pentose and glucuronate interconversions & 0.275 & $0.076^{*}$ & 0.199 \\
\hline Pentose phosphate pathway & 0.480 & $0.125^{*}$ & 0.358 \\
\hline Propanoate metabolism & 0.722 & $0.196^{*}$ & 0.557 \\
\hline Starch and sucrose metabolism & 0.340 & $0.097 *$ & 0.232 \\
\hline Carbohydrate metabolism & 0.058 & $0.018^{*}$ & 0.033 \\
\hline \multicolumn{4}{|l|}{ Lipid Metabolism } \\
\hline alpha-Linolenic acid metabolism & 0.036 & $0.009 *$ & 0.028 \\
\hline Biosynthesis of unsaturated fatty acids & 0.193 & $0.053 *$ & 0.137 \\
\hline Ether lipid metabolism & 0.057 & $0.013 *$ & 0.042 \\
\hline Fatty acid biosynthesis & 0.417 & $0.109 *$ & 0.313 \\
\hline Fatty acid metabolism & 0.606 & $0.163 *$ & 0.472 \\
\hline Glycerolipid metabolism & 0.231 & $0.060^{*}$ & 0.171 \\
\hline Lipid biosynthesis proteins & 0.664 & $0.173 *$ & 0.505 \\
\hline Sphingolipid metabolism & 0.050 & $0.015^{*}$ & 0.029 \\
\hline Steroid hormone biosynthesis & 0.018 & $0.005 *$ & 0.014 \\
\hline Synthesis and degradation of ketone bodies & 0.145 & $0.039 *$ & 0.111 \\
\hline \multicolumn{4}{|l|}{ Metabolism of Terpenoids and Polyketides } \\
\hline Biosynthesis of 12-, 14- and 16-membered macrolides & 0.001 & $0.000^{*}$ & $0.000 *$ \\
\hline Carotenoid biosynthesis & 0.022 & $0.005^{*}$ & 0.015 \\
\hline Geraniol degradation & 0.249 & $0.072 *$ & 0.189 \\
\hline Limonene and pinene degradation & 0.283 & $0.080^{*}$ & 0.214 \\
\hline Prenyltransferases & 0.181 & $0.049 *$ & 0.133 \\
\hline Terpenoid backbone biosynthesis & 0.310 & $0.085^{*}$ & 0.232 \\
\hline \multicolumn{4}{|l|}{ Xenobiotics Biodegradation and Metabolism } \\
\hline Aminobenzoate degradation & 0.392 & $0.106^{*}$ & 0.302 \\
\hline Benzoate degradation & 0.462 & $0.129^{*}$ & 0.355 \\
\hline Bisphenol degradation & 0.088 & $0.027 *$ & 0.064 \\
\hline Caprolactam degradation & 0.168 & $0.048^{*}$ & 0.129 \\
\hline Chloroalkane and chloroalkene degradation & 0.183 & $0.049^{*}$ & 0.138 \\
\hline Chlorocyclohexane and chlorobenzene degradation & 0.051 & $0.018^{*}$ & 0.036 \\
\hline Dioxin degradation & 0.055 & $0.014 *$ & 0.042 \\
\hline Drug metabolism - other enzymes & 0.155 & $0.042 *$ & 0.121 \\
\hline Ethylbenzene degradation & 0.064 & $0.019^{*}$ & 0.051 \\
\hline Fluorobenzoate degradation & 0.036 & $0.010^{*}$ & 0.023 \\
\hline Naphthalene degradation & 0.195 & $0.056^{*}$ & 0.152 \\
\hline Nitrotoluene degradation & 0.054 & $0.018^{*}$ & 0.043 \\
\hline Polycyclic aromatic hydrocarbon degradation & 0.083 & $0.027^{*}$ & 0.058 \\
\hline Toluene degradation & 0.133 & $0.038 *$ & 0.096 \\
\hline Xylene degradation & 0.022 & $0.007 *$ & 0.012 \\
\hline \multicolumn{4}{|l|}{ Other metabolic pathways } \\
\hline Carbon fixation pathways in prokaryotes & 0.692 & $0.188^{*}$ & 0.540 \\
\hline Methane metabolism & 0.677 & $0.181^{*}$ & 0.530 \\
\hline Glycosyltransferases & 0.245 & $0.063 *$ & 0.189 \\
\hline Retinol metabolism & 0.061 & $0.017 *$ & 0.046 \\
\hline Thiamine metabolism & 0.206 & $0.052 *$ & 0.150 \\
\hline
\end{tabular}


Table 5. Continued

\begin{tabular}{|c|c|c|c|}
\hline \multirow{2}{*}{ KEGG pathway } & \multicolumn{3}{|c|}{ Gene frequency $(\mathrm{HN})$} \\
\hline & Col-0 & nlp7-1 & tcp20-4 \\
\hline \multicolumn{4}{|l|}{ Cellular Processes and Signaling } \\
\hline Other transporters & 0.160 & $0.039 *$ & 0.115 \\
\hline \multicolumn{4}{|l|}{ Environmental Information Processing } \\
\hline Phosphotransferase system (PTS) & 0.064 & $0.019 *$ & 0.050 \\
\hline Transporters & 5.047 & $1.447 *$ & 4.043 \\
\hline Phosphatidylinositol signaling system & 0.059 & $0.016^{*}$ & 0.046 \\
\hline Bacterial toxins & 0.082 & $0.021^{*}$ & 0.062 \\
\hline \multicolumn{4}{|l|}{ Others } \\
\hline Proteasome & 0.031 & $0.008^{*}$ & 0.021 \\
\hline Protein export & 0.317 & $0.082 *$ & 0.237 \\
\hline Base excision repair & 0.337 & $0.086^{*}$ & 0.251 \\
\hline Mismatch repair & 0.373 & $0.096^{*}$ & 0.280 \\
\hline Non-homologous end-joining & 0.068 & $0.017 *$ & 0.048 \\
\hline Nucleotide excision repair & 0.223 & $0.057^{*}$ & 0.165 \\
\hline Pathways in cancer & 0.041 & $0.011^{*}$ & 0.032 \\
\hline Prostate cancer & 0.020 & $0.005^{*}$ & 0.015 \\
\hline Staphylococcus aureus infection & 0.001 & $0.000 *$ & 0.000 \\
\hline Tuberculosis & 0.098 & $0.025^{*}$ & 0.073 \\
\hline Prion diseases & 0.002 & $0.000 *$ & $0.001 *$ \\
\hline Adipocytokine signaling pathway & 0.095 & $0.024^{*}$ & 0.073 \\
\hline PPAR signaling pathway & 0.185 & $0.048^{*}$ & 0.141 \\
\hline Progesterone-mediated oocyte maturation & 0.020 & $0.005^{*}$ & 0.015 \\
\hline Vasopressin-regulated water reabsorption & 0.001 & $0.000^{*}$ & $0.000 *$ \\
\hline Antigen processing and presentation & 0.020 & $0.005 *$ & 0.015 \\
\hline NOD-like receptor signaling pathway & 0.020 & $0.005^{*}$ & 0.015 \\
\hline
\end{tabular}

* indicates a significant difference $(P<0.05)$ between the wild-type (Col-0) and $n l p 7-1$ or $t c p 20-4$ according to Welch's $t$-test. $\mathrm{HN}$, high (240 $\left.\mathrm{mg} \mathrm{N} \mathrm{kg}^{-1}\right)$ nitrate supply. Values represent means $(n=3)$.

\section{Acknowledgements}

This study was supported by a Grant-in-Aid from the Tohoku University Division for Interdisciplinary Advanced Research and Education, grants from the Ministry of Agriculture, Forestry, and Fisheries, Japan (BRAIN), and Grants-in-Aid for Scientific Research (A) 23248052 and 26252065 from the Ministry of Education, Culture, Sports, Science and Technology, Japan. We thank Hirohito Tsurumaru (Kagoshima University) for his technical support with RISA.

\section{References}

1. Alvarez, J.M., E. Riveras, E.A. Vidal, et al. 2014. Systems approach identifies TGA1 and TGA4 transcription factors as important regulatory components of the nitrate response of Arabidopsis thaliana roots. Plant J. 80:1-13.

2. Andrews, M., J.A. Raven, and P.J. Lea. 2013. Do plants need nitrate? The mechanisms by which nitrogen form affects plants. Ann. Appl. Biol. 163:174-199.

3. Araya, T., M. Miyamoto, J. Wibowo, et al. 2014. CLE-CLAVATA1 peptide-receptor signaling module regulates the expansion of plant root systems in a nitrogen-dependent manner. Proc. Natl. Acad. Sci. U.S.A. 111:2029-2034.

4. Bao, Z., A. Watanabe, K. Sasaki, et al. 2014. A rice gene for microbial symbiosis, Oryza sativa $C C a M K$, reduces $\mathrm{CH}_{4}$ flux in a paddy field with low nitrogen input. Appl. Environ. Microbiol. 80:1995-2003.

5. Bhattacharyya, P.N., and D.K. Jha. 2012. Plant growth-promoting rhizobacteria (PGPR): emergence in agriculture. World J. Microbiol. Biotechnol. 28:1327-1350.

6. Bodenhausen, N., M.W. Horton, and J. Bergelson. 2013. Bacterial communities associated with the leaves and the roots of Arabidopsis thaliana. PLoS One 8:e56329.

7. Bulgarelli, D., M. Rott, K. Schlaeppi, et al. 2012. Revealing structure and assembly cues for Arabidopsis root-inhabiting bacterial microbiota. Nature 488:91-95.

8. Bulgarelli, D., K. Schlaeppi, S. Spaepen, E.V.L. van Themaat, and P. Schulze-Lefert. 2013. Structure and functions of the bacterial microbiota of plants. Annu. Rev. Plant Biol. 64:807-838.
9. Caba, J.M., M.L. Centeno, B. Fernández, P.M. Gresshoff, and F. Ligero. 2000. Inoculation and nitrate alter phytohormone levels in soybean roots: differences between a supernodulating mutant and the wild type. Planta 211:98-104.

10. Caporaso, J.G., J. Kuczynski, J. Stombaugh, et al. 2010. QIIME allows analysis of high-throughput community sequencing data. Nat. Methods 7:335-336.

11. Caporaso, J.G., C.L. Lauber, W.A. Walters, D. Berg-Lyons, C.A. Lozupone, P.J. Turnbaugh, N. Fierer, and R. Knight. 2011. Global patterns of $16 \mathrm{~S}$ rRNA diversity at a depth of millions of sequences per sample. Proc. Natl. Acad. Sci. U.S.A. 108:4516-4522.

12. Castaings, L., A. Camargo, D. Pocholle, et al. 2009. The nodule inception-like protein 7 modulates nitrate sensing and metabolism in Arabidopsis. Plant J. 57:426-435.

13. Chen, X., L. Miché, S. Sachs, et al. 2015. Rice responds to endophytic colonization which is independent of the common symbiotic signaling pathway. New Phytol. 208:531-543.

14. Diallo, M.D., B. Reinhold-Hurek, and T. Hurek. 2008. Evaluation of PCR primers for universal nifH gene targeting and for assessment of transcribed nifH pools in roots of Oryza longistaminata with and without low nitrogen input. FEMS Microbiol. Ecol. 65:220-228.

15. Edgar, R.C. 2010. Search and clustering orders of magnitude faster than BLAST. Bioinformatics 26:2460-2461

16. Foo, E., K. Yoneyama, C.J. Hugill, L.J. Quittenden, and J.B. Reid. 2013. Strigolactones and the regulation of pea symbioses in response to nitrate and phosphate deficiency. Mol. Plant 6:76-87.

17. Gan, Y., A. Bernreiter, S. Filleur, B. Abram, and B.G. Forde. 2012. Overexpressing the ANR1 MADS-box gene in transgenic plants provides new insights into its role in the nitrate regulation of root development. Plant Cell Physiol. 53:1003-1016.

18. Giagnoni, L., R. Pastorelli, S. Mocali, M. Arenella, P. Nannipieri, and G. Renella. 2016. Availability of different nitrogen forms changes the microbial communities and enzyme activities in the rhizosphere of maize lines with different nitrogen use efficiency. Appl. Soil. Ecol. 98:30-38.

19. Guan, P., R. Wang, P. Nacry, et al. 2014. Nitrate foraging by Arabidopsis roots is mediated by the transcription factor TCP20 through the systemic signaling pathway. Proc. Natl. Acad. Sci. U.S.A. 111:15267-15272.

20. Hachiya, T., I. Terashima, and K.O. Noguchi. 2007. Increase in respiratory cost at high growth temperature is attributed to high protein turnover cost in Petunia $\times$ hybrida petals. Plant Cell Environ. 30:1269-1283. 
21. Ho, C.H., S.H. Lin, H.C. Hu, and Y.F. Tsay. 2009. CHL1 functions as a nitrate sensor in plants. Cell 138:1184-1194.

22. Hu, H.C., Y.Y. Wang, and Y.F. Tsay. 2009. AtCIPK8, a CBL-interacting protein kinase, regulates the low-affinity phase of the primary nitrate response. Plant J. 57:264-278.

23. Ikeda, S., T. Okubo, M. Anda, et al. 2010. Community- and genomebased views of plant-associated bacteria: Plant-bacterial interactions in soybean and rice. Plant Cell Physiol. 51:1398-1410.

24. Ikeda, S., T. Ohkubo, T. Kaneko, et al. 2010. Community shifts of soybean stem-associated bacteria responding to different nodulation phenotypes and N levels. ISME J. 4:315-326.

25. Ikeda, S., T. Okubo, N. Takeda, et al. 2011. The genotype of the calcium/calmodulin-dependent protein kinase gene (CCaMK) determines bacterial community diversity in rice roots under paddy and upland field conditions. Appl. Environ. Microbiol. 77:4399-4405.

26. Ikeda, S., K. Sasaki, T. Okubo, et al. 2014. Low nitrogen fertilization adapts rice root microbiome to low nutrient environment by changing biogeochemical functions. Microbes Environ. 29:50-59.

27. Kamada-Nobusada, T., N. Makita, M. Kojima, and H. Sakakibara. 2013. Nitrogen-dependent regulation of de novo cytokinin biosynthesis in rice: the role of glutamine metabolism as an additional signal. Plant Cell Physiol. 54:1881-1893.

28. Konishi, M., and S. Yanagisawa. 2013. Arabidopsis NIN-like transcription factors have a central role in nitrate signaling. Nat. Commun. 4:1617.

29. Konishi, N., K. Ishiyama, K. Matsuoka, I. Maru, T. Hayakawa, T. Yamaya, and S. Kojima. 2014. NADH-dependent glutamate synthase plays a crucial role in assimilating ammonium in the Arabidopsis root. Physiol. Plantarum 152:138-151.

30. Krouk, G., P. Mirowski, Y. Le Cun, D.E. Shasha, and G.M. Coruzzi. 2010. Predictive network modeling of the high-resolution dynamic plant transcriptome in response to nitrate. Genome Biol. 11:R123.

31. Langille, M.G.I., J. Zaneveld, J.G. Caporaso, et al. 2013. Predictive functional profiling of microbial communities using 16S rRNA marker gene sequences. Nat. Biotechnol. 31:814-821.

32. Lebeis, S.L., S.H. Paredes, D.S. Lundberg, et al. 2015. Salicylic acid modulates colonization of the root microbiome by specific bacterial taxa. Science 349:860-864.

33. Lundberg, D.S., S.L. Lebeis, S.H. Paredes, et al. 2012. Defining the core Arabidopsis thaliana root microbiome. Nature 488:86-90.

34. Marchive, C., F. Roudier, L. Castaings, et al. 2013. Nuclear retention of the transcription factor NLP7 orchestrates the early response to nitrate in plants. Nat. Commun. 4:1713.

35. Martín-Trillo, M., and P. Cubas. 2010. TCP genes: a family snapshot ten years later. Trends Plant Sci. 15:31-39.

36. Minamisawa, K., H. Imaizumi-Anraku, Z. Bao, R. Shinoda, T. Okubo, and S. Ikeda. 2016. Are symbiotic methanotrophs key microbes for $\mathrm{N}$ acquisition in paddy rice root? Microbes Environ. 31(1):4-10.

37. Nishida, H., Y. Handa, S. Tanaka, T. Suzaki, and M. Kawaguchi. 2016. Expression of the $C L E-R S 3$ gene suppresses root nodulation in Lotus japonicus. J. Plant Res. 129:909-919.

38. Nishio, T., and T. Arao. 2002. Difference in the amount of $\mathrm{N}$ Immobilization among 4 soils treated with ${ }^{15} \mathrm{~N}$-Labelled ammonium sulfate. J. Sci. Soil Manure Jap. 73:493-499 (In Japanese).

39. Okamoto, S., E. Ohnishi, S. Sato, H. Takahashi, M. Nakazono, S. Tabata, and M. Kawaguchi. 2009. Nod factor/nitrate-induced CLE genes that drive HAR1-mediated systemic regulation of nodulation. Plant Cell Physiol. 50:67-77.

40. Paradiso, R., R. Buonomo, M.A. Dixon, G. Barbieri, and S. De Pascale. 2015. Effect of bacterial root symbiosis and urea as source of nitrogen on performance of soybean plants grown hydroponically for Bioregenerative Life Support Systems (BLSSs). Front. Plant Sci. 6:888.

41. Remans, T., P. Nacry, M. Pervent, et al. 2006. The Arabidopsis NRT1. 1 transporter participates in the signaling pathway triggering root colonization of nitrate-rich patches. Proc. Natl. Acad. Sci. U.S.A. 103:19206-19211.
42. Robinson, R.J., B.A. Fraaije, I.M. Clark, R.W. Jackson, P.R. Hirsch, and T.H. Mauchline. 2016. Endophytic bacterial community composition in wheat (Triticum aestivum) is determined by plant tissue type, developmental stage and soil nutrient availability. Plant Soil 405:381396.

43. Rodríguez-Blanco, A., M. Sicardi, and L. Frioni. 2015. Plant genotype and nitrogen fertilization effects on abundance and diversity of diazotrophic bacteria associated with maize (Zea mays L.). Biol. Fert. Soils 51:391-402.

44. Rubin, G., T. Tohge, F. Matsuda, K. Saito, and W.R. Scheible. 2009. Members of the $L B D$ family of transcription factors repress anthocyanin synthesis and affect additional nitrogen responses in Arabidopsis. Plant Cell. 21:3567-3584.

45. Ruffel, S., A. Gojon, and L. Lejay. 2014. Signal interactions in the regulation of root nitrate uptake. J. Exp. Bot. 65:5509-5517.

46. Rybakova, D., T. Cernava, M. Köberl, S. Liebminger, M. Etemadi, and G. Berg. 2016. Endophytes-assisted biocontrol: novel insights in ecology and the mode of action of Paenibacillus. Plant Soil 405:125140.

47. Rybakova, D., M. Schmuck, U. Wetzlinger, A. Varo-Suarez, O. Murgu, H. Müller, and G. Berg. 2016. Kill or cure? The interaction between endophytic Paenibacillus and Serratia strains and the host plant is shaped by plant growth conditions. Plant Soil 405:65-79.

48. Saito, A., S. Ikeda, C. Noritake, M. Akasaka, K. Fujishiro, K. Ando, and K. Minamisawa. 2008. Evaluation of microbial diversity using ribosomal intergenic spacer analysis. Jap. Soc. Microbiol. Ecol. 22:59-71 (In Japanese).

49. Sakakibara, H., K. Takei, and N. Hirose. 2006. Interactions between nitrogen and cytokinin in the regulation of metabolism and development. Trends Plant Sci. 11:440-448.

50. Santi, C., D. Bogusz, and C. Franche. 2013. Biological nitrogen fixation in non-legume plants. Ann. Bot. 111:743-767.

51. Sasaki, K., S. Ikeda, T. Ohkubo, C. Kisara, T. Sato, and K. Minamisawa. 2013. Effects of plant genotype and nitrogen level on bacterial communities in rice shoots and roots. Microbes Environ. 28:391-395.

52. Schauser, L., W. Wieloch, and J. Stougaard. 2005. Evolution of NINlike proteins in Arabidopsis, rice, and Lotus japonicus. J. Mol. Evol. 60:229-237.

53. Schlaeppi, K., N. Dombrowski, R.G. Oter, E.V.L. van Themaat, and P. Schulze-Lefert. 2014. Quantitative divergence of the bacterial root microbiota in Arabidopsis thaliana relatives. Proc. Natl. Acad. Sci. U.S.A. 111:585-592.

54. Soyano, T., and M. Hayashi. 2014. Transcriptional networks leading to symbiotic nodule organogenesis. Curr. Opin. Plant Biol. 20:146154.

55. Soyano, T., Y. Shimoda, and M. Hayashi. 2014. NODULE INCEPTION antagonistically regulates gene expression with nitrate in Lotus japonicus. Plant Cell Physiol. 56:368-376.

56. Tan, Z., T. Hurek, and B. Reinhold-Hurek. 2003. Effect of N-fertilization, plant genotype and environmental conditions on nifH gene pools in roots of rice. Environ. Microbiol. 5:1009-1015.

57. Tkacz, A., and P. Poole. 2015. Role of root microbiota in plant productivity. J. Exp. Bot. 66:2167-2175.

58. Vacheron, J., G. Desbrosses, M.L. Bouffaud, B. Touraine, and C. Prigent-Combaret. 2013. Plant growth-promoting rhizobacteria and root system functioning. Front. Plant Sci. doi: 10.3389/fpls.2013.00356.

59. Wang, R., X. Xing, Y. Wang, A. Tran, and N.M. Crawford. 2009. A genetic screen for nitrate regulatory mutants captures the nitrate transporter gene NRT1.1. Plant Physiol. 151:472-478.

60. Yeoh, Y.K., C. Paungfoo-Lonhienne, P.G. Dennis, N. Robinson, M.A. Ragan, S. Schmidt, and P. Hugenholtz. 2015. The core root microbiome of sugarcanes cultivated under varying nitrogen fertilizer application. Environ. Microbiol. 18:1338-1351.

61. Zhang, H., and B.G. Forde. 1998. An Arabidopsis MADS box gene that controls nutrient-induced changes in root architecture. Science 279:407-409.

62. Zhu, H., B.K. Riely, N.J. Burns, and J.M. Ané. 2006. Tracing nonlegume orthologs of legume genes required for nodulation and arbuscular mycorrhizal symbioses. Genetics 172:2491-2499. 